\title{
Characterization of the Gene Encoding Human Sarcolipin (SLN), a Proteolipid Associated with SERCA1: Absence of Structural Mutations in Five Patients with Brody Disease
}

\author{
Alex Odermatt,* Peter E. M. Taschner,† Stephen W. Scherer,‡ Barbara Beatty,§ \\ Vijay K. Khanna,* David R. Cornblath," Vinay Chaudhry," Won-Chee Yee, $\|$ \\ Bertold Schrank,** George Karpati, †† Martijn H. Breuning, $\dagger \nmid \ddagger$ \\ Nine Knoers, $\S \S$ and David H. MacLennan*,1
}

\begin{abstract}
*Banting and Best Department of Medical Research, University of Toronto, Charles H. Best Institute, 112 College Street, Toronto, Ontario, Canada M5G 1L6; †Department of Human Genetics, Sylvius Laboratories, Leiden University, P.O. Box 9503,

Wassenaarseweg 72, 2300 RA Leiden, The Netherlands; $¥$ Department of Genetics, The Hospital for Sick Children, 555 University Avenue, Toronto, Ontario, Canada M 5G 1X8; §Department of Pathology, University of Toronto, Ontario Cancer Institute, Princess M argaret Hospital, 610 University Avenue, Toronto, Ontario, Canada M 5G 2M 9; 'Department of Neurology, Johns Hopkins University School of Medicine, 600 North Wolfe Street, Baltimore, Maryland 21205; |Department of Neurology, Washington University School of Medicine, 660 Euclid, St. Louis, Missouri 63110;

$* *$ Neurologische Universitätsklinik, Josef-Schneider-Strasse 11, 97080 Würzburg, Germany; ††M ontreal Neurological Institute, McGill University, 3801 Rue University, Montreal, Quebec, Canada H3A 2B4; $¥ \ddagger$ Department of Clinical Genetics, Erasmus University, Dr. M olewaterplein 50, P.O. Box 1738, 3000 DR Rotterdam, The Netherlands; and §§Department of Human Genetics, University Hospital Nijmegen, P.O. Box 9101, 6500 HB Nijmegen, The Netherlands
\end{abstract}

Received April 14, 1997; accepted August 7, 1997

Sarcolipin (SLN) is a low-molecular-weight protein that copurifies with the fast-twitch skeletal muscle sarcoplasmic reticulum $\mathrm{Ca}^{2+}$ ATPase (SE RCA1). Genomic DNA and CDNA encoding human sarcolipin (SLN) were isolated and characterized and the SLN gene was mapped to chromosome 11q22-q23. Human, rabbit, and mouse cDNAs encode a protein of 31 amino acids. Homology of SLN with phospholamban (PLN) suggests that the first 7 hydrophilic amino acids are cytoplasmic, the next 19 hydrophobic amino acids form a single transmembrane helix, and the last 5 hydrophilic amino acids are lumenal. The cytoplasmic and transmembrane sequences are not well conserved among the three species, but the lumenal sequence is highly conserved. Like SERCA1, SLN is highly expressed in rabbit fast-twitch skeletal muscle, but it is expressed to a lower extent in slow-twitch muscle and to an even lower extent in cardiac muscle, where SE RCA2a and PLN are highly expressed. It is expressed in only trace amounts in pancreas and prostate. SLN and PLN genes resemble each other in having two small exons, with their entire coding sequences lying in exon 2 and a large intron separating the two segments. Brody dis-

Sequence data from this article have been deposited with the GenBank/EMBL Data Libraries under Accession Nos. U96091, rabbit CDNA; U96092, U96093, human gDNA; U96094, human CDNA.

${ }^{1}$ To whom correspondence should be addressed. Telephone (416) 978-5008. Fax: (416) 978-8528. E-mail: david.maclennan@ utoronto.ca. ease is an inherited disorder of skeletal muscle function, characterized by exercise-induced impairment of muscle relaxation. Mutations in the ATP2A1 gene encoding SERCA1 have been associated with the autosomal recessive inheritance of Brody disease in three families, but not with autosomal dominant inheritance of the disease. A search for mutations in the SLN gene in five Brody families, four of which were not linked to ATP2A1, did not reveal any alterations in coding, splice junction or promoter sequences. The homozygous deletion of $\mathrm{C} 438$ in the coding sequence of ATP2A1 in Brody disease family 3, leading to a frameshift and truncation following Pro $_{147}$ in SERCA1, is the fourth ATP2A1 mutation to be associated with autosomal recessive Brody disease. 1997 Academic Press

\section{INTRODUCTION}

\section{Sarcolipin}

Sarcolipin (SLN) was first isolated as a low-molecular-weight proteolipid from rabbit fast-twitch skeletal muscle sarcoplasmic reticulum and from preparations of the $\mathrm{Ca}^{2+}$ ATPase(SERCA1) purified from that source (MacLennan et al., 1972). Attempts were made to discover a function for SLN, by reconstitution of the proteolipid with purified preparations of SERCA1 and measurement of any alteration in SERCA1 function. 
SLN was reported to enhance the coupling ratio between $\mathrm{Ca}^{2+}$ uptake and $\mathrm{Ca}^{2+}$-dependent ATP hydrolysis when reconstituted with SERCA1, but, when purified SLN was added to the exterior of these reconstituted liposomes, $\mathrm{Ca}^{2+}$ accumulation was diminished, implying that SLN might act as a $\mathrm{Ca}^{2+}$ ionophore (Racker and Eytan, 1975). MacLennan et al. (1980) fractionated SLN away from SERCA1, reconstituted the highly purified SERCA1 in lipid bilayers, and found no alteration in $\mathrm{Ca}^{2+} / \mathrm{ATP}$ coupling ratios before and after removal of SLN. Later studies by Maruyama and MacLennan (1988) showed that SERCA1 CDNA, expressed alone in heterologous cell culture, yielded microsomal membranes containing fully functional $\mathrm{Ca}^{2+}$ uptake and $\mathrm{Ca}^{2+}$-dependent ATPase activities, suggesting that SLN plays no essential role in $\mathrm{Ca}^{2+}$ uptake. The protein was sequenced by Wawrzynow et al. (1992) and named sarcolipin.

In studies of the yeast $\mathrm{H}^{+}$ATPase, Navarre et al. (1992) discovered that two low-molecular-weight proteolipids are associated with this P-type ATPase. In double mutants, lacking both proteolipids, the $\mathrm{V}_{\max }$ of the $\mathrm{H}^{+}$ATPase was reduced to $50 \%$ of that of wild type strains (Navarre et al., 1994). The mechanism of interaction of these proteolipids with the $\mathrm{H}^{+}$ATPase has not been determined.

Phospholamban (PLN) is a 52-amino-acid protein located in the sarcoplasmic reticulum of cardiac, slowtwitch, and smooth muscles, where it acts as an inhibitor of SERCA2 by lowering its apparent affinity for $\mathrm{Ca}^{2+}$ (Tada and Katz, 1982). The protein has a hydrophilic N-terminal sequence of 30 amino acids, which would alter its solubility by comparison with low-molecular-weight proteolipids, but, in respect to its interaction with a P-type cation pump, it resembles other proteolipids.

In this paper, we characterize the sarcolipin (SLN) gene and demonstrate structural similarities between the SLN and PLN genes, as well as homology between the peptide sequences of their products. SLN genetranscription is shown to be high in fast-twitch skeletal muscle, where SERCA1 expression predominates. By contrast, PLN gene transcription was shown earlier to be high in cardiac muscle, where SERCA2a expression predominates (Fujii et al., 1988).

\section{Brody Disease}

Brody disease is an inherited disorder of skeletal muscle function, characterized by exercise-induced impairment of musclerelaxation. Studies of the sarcoplasmic reticulum from Brody patients have shown decreased $\mathrm{Ca}^{2+}$ uptake and $\mathrm{Ca}^{2+}$-dependent ATP hydrolysis. (Brody, 1969; Karpati et al., 1986: Danon et al., 1988; Taylor et al., 1988; Wevers et al., 1992; Poels et al., 1993; Benders et al., 1994). In the studies of Karpati et al. (1986), no immunologically reactive ATPase was observed in fast-twitch fibers of probands from two
Brody families. In later studies, Benders et al. (1994) were unable to measure a decrease in SERCA1 protein content in skeletal muscle from seven Brody families, but SERCA1 activity was reduced by $50 \%$.

We have reported the association of some cases of Brody disease with the autosomal recessive inheritance of mutations in the ATP2A1 gene, encoding SERCA1, in two Brody families (Odermatt et al., 1996), but ATP2A1 was ruled out as a candidate gene in three other Brody families in an earlier study (Zhang et al., 1995), demonstrating that the cause of the disease is heterogeneous. Some of the non-ATP2A1-linked families were characterized by dominant inheritance of the disease. Since SERCA1 content was reported to be normal, but with reduced activity in seven Brody patients studied by Benders et al. (1994), we deduced that a candidate gene for Brody disease might encode a protein that would interact with SERCA1 and, when mutated, become a dominant inhibitor of SERCA1 function. Accordingly, the human SLN gene was evaluated as a candidate gene for Brody disease. Unfortunately, we were unable to find any alterations in coding, splice junction, or promoter sequences that would support SLN as a candidate gene for Brody disease in five patients.

\section{MATERIALS AND METHODS}

\begin{abstract}
Preparation of RNA and RT-PCR. Total RNA was isolated from normal human skeletal muscle using guanidium-isothiocyanatephenol-chloroform extraction (Chomczynski and Sacchi, 1987). A 5$\mu \mathrm{g}$ aliquot of total RNA was reverse transcribed in $50 \mu \mathrm{l}$ of a reaction mix (Stratagene cDNA synthesis kit) containing $50 \mathrm{U}$ of MMULV reverse transcriptase at $37^{\circ} \mathrm{C}$ in the presence of RNase Block Inhibitor and $0.5 \mu \mathrm{g}$ of random primers. Following first-strand CDNA synthesis, RNA was hydrolyzed by the addition of $50 \mu$ l of $0.3 \mathrm{~N}$ sodium hydroxide and $30 \mathrm{mM}$ EDTA and boiling for $5 \mathrm{~min}$. The $\mathrm{pH}$ was then neutralized with $25 \mu \mathrm{l}$ of Tris- $\mathrm{HCl}, \mathrm{pH}$ 8.3. After extraction with phenol and chloroform, the cDNA was precipitated with ethanol and washed, and the pellet was dissolved in $30 \mu \mathrm{l}$ of $\mathrm{H}_{2} \mathrm{O}$. Aliquots of 1 $\mu \mathrm{l}$ of first-strand CDNA were used as the template in subsequent
\end{abstract} PCR amplifications.

PCR cloning of partial SLN CDNA based on known peptide se quence. Reverse translation of the amino acid sequence of rabbit sarcolipin (Wawrzynow et al., 1992) permitted the synthesis of two fully degenerate oligonucleotide primers, SALF 7 and SALR7 (Table 1 ), based on the $5^{\prime}$ and $3^{\prime}$ ends of the CDNA coding sequence. The oligonucleotide primers also contained nine nucleotide BamHI restriction endonuclease sites at their $5^{\prime}$ ends to facilitate subsequent cloning of PCR products. PCR amplification with primers SALF 7 and SALR7 was carried out using either $100 \mathrm{ng}$ of DNA from a fulllength rabbit skel etal muscle cDNA library (MacLennan et al., 1985) constructed in the pcDX vector (Okayama and Berg, 1983) or, alternatively, using $1 \mu \mathrm{l}$ of first-strand CDNA derived from normal human skeletal muscle as a template. Taq polymerase and Taq Extender (Stratagene) were used for PCR amplification in the buffer supplied. Denaturation was for $1 \mathrm{~min}$ at $94^{\circ} \mathrm{C}$, annealing was at $57^{\circ} \mathrm{C}$ for 2 min, and extension for 30 cycles was at $72^{\circ} \mathrm{C}$ for $2 \mathrm{~min}$, followed by a final extension at $72^{\circ} \mathrm{C}$ for $10 \mathrm{~min}$. Amplified DNA obtained using either rabbit or human template was cloned into the BamHI site of the Bluescript vector BsKs(+) (Stratagene). The coding sequence between degenerate primers was $45 \mathrm{bp}$ long for both the rabbit and the human SLN genes. 
TABLE 1

\begin{tabular}{|c|c|c|c|c|}
\hline Primer & & Sequence & & Description \\
\hline SALF 7 & $5^{\prime}$ & $\begin{array}{l}\text { ACAGGATCCATGGA (AG) (AC) G (ACGT) (AT) (CG) } \\
\text { (ACGT) AC (ACGT) (AC) G (ACGT) GA (AG) C }\end{array}$ & $3^{\prime}$ & (Degenerated PCR) \\
\hline SALR7 & $5^{\prime}$ & $\begin{array}{l}\text { ACAGGATCCTG (AG) TA (ACGT) (CG) (AT) (ACGT) } \\
\text { C (GT) (ACGT) AC (ACGT) A (AG) (ACGT) A (AG) CC }\end{array}$ & $3^{\prime}$ & (Degenerated PCR) \\
\hline SALF9 & $5^{\prime}$ & CTTGGATCCGTTGTCCTTATTACAGTGATCC & $3^{\prime}$ & (Inverse PCR, \\
\hline SALR9 & $5^{\prime}$ & CAAGGATCCACAGTGAAGTTGAGACACAGC & $3^{\prime}$ & rabbit SLN) \\
\hline RSAF 7 & $5^{\prime}$ & TAAGGATCCACACAGCCTGGGAGATGAGCC & $3^{\prime}$ & (cDNA cloning, \\
\hline RSAR8 & $5^{\prime}$ & TAAGGATCCGTGGTTGACTTAACTTTATTCACATG & $3^{\prime}$ & rabbit SLN) \\
\hline RACE 1 & $5^{\prime}$ & CAGCCTTGACTTGAGCAGTAGCTGAGACTCAAGTCG & & \\
\hline & & TGTTTTTTTTTTTTTTTTTT & $3^{\prime}$ & (3' RACE) \\
\hline RACE3 & $5^{\prime}$ & GTTGGATCCAGTAGCTGAGACTCAAGTCGTG & $3^{\prime}$ & (3'RACE) \\
\hline SALF10 & $5^{\prime}$ & CAAGGATCCGAGCTGTGTCTCAACTTCAC & $3^{\prime}$ & (Inverse PCR, \\
\hline SALR10 & $5^{\prime}$ & CAAGGATCCAGGATCACTGTAATAAGGACAAC & $3^{\prime}$ & human SLN) \\
\hline HSAF 5 & $5^{\prime}$ & GTTGGAGCTCAAGTTGGAGACAGCGAG & $3^{\prime}$ & (cDNA cloning, \\
\hline HSAR5 & $5^{\prime}$ & GTTGAGCTCGTTGACTTAACTTTATTCACATGATAG & $3^{\prime}$ & human SLN) \\
\hline HSAF 1 & $5^{\prime}$ & GTTGGATCCTTGATTACGGTTATTCTTATGTG & $3^{\prime}$ & (Inverse PCR, human \\
\hline HSAR1 & $5^{\prime}$ & GAAGGATCCACAATAGTGAAGTTGAGAAACAG & $3^{\prime}$ & 3' flanking gDNA) \\
\hline HSAF8 & $5^{\prime}$ & GATTCTAGAGTCTTTGATCCTCTTCAGGTAACTG & $3^{\prime}$ & (Inverse PCR, human \\
\hline HSAR8 & $5^{\prime}$ & TACTCTAGACTATGGCAGGTTTCTCCTCGCTG & $3^{\prime}$ & $\begin{array}{l}5 \text { flanking gDNA) } \\
\text { (Primer extension) }\end{array}$ \\
\hline HSAF3 & $5^{\prime}$ & GTCCTGGGATTGACTGAG & $3^{\prime}$ & (Detection of a minor \\
\hline HSAR11 & $5^{\prime}$ & ССTCTGCCCTTCAGACTAG & $3^{\prime}$ & human mRNA transcript) \\
\hline HSAF 12 & $5^{\prime}$ & AAACCCACATCAATTGCAC & $3^{\prime}$ & ( $5^{\prime}$ region probe) \\
\hline HSAF9 & $5^{\prime}$ & AGAACGGGCATTGTTATACAGG & $3^{\prime}$ & (Mapping, human SLN) \\
\hline HPE 1 & $5^{\prime}$ & TTTCTGAGGGCACACCAAGGACCTCTGGCTTG & $3^{\prime}$ & (Primer extension) \\
\hline
\end{tabular}

Cloning of rabbit SLN cDNA. Knowledge of the 45-bp sequence of rabbit SLN CDNA lying between primers SALF 7 and SALR 7 (Table 1) permitted the design of additional primers (SALF9, SALR9) for inverse long PCR amplification in which the CDNA and the whole pCDX vector sequence were included. PCR amplification was carried out with Taq polymerase:Pfu polymerase (5:1 ratio), using $100 \mathrm{ng}$ of the full-length rabbit skeletal muscle cDNA library in pCDX as a template. An initial hot start at $94^{\circ} \mathrm{C}$ for $2 \mathrm{~min}$ preceded 30 cycles of denaturation at $94^{\circ} \mathrm{C}$ for $30 \mathrm{~s}$, annealing at $62^{\circ} \mathrm{C}$ for $1 \mathrm{~min}$, and elongation at $72^{\circ} \mathrm{C}$ for $10 \mathrm{~min}$. A single product of about $4.5 \mathrm{~kb}$ was purified on a $1 \%$ agarose gel and extracted with a gel extraction kit from Qiagen. About $10 \mathrm{ng}$ of the product was then blunt ended by incubation with $0.7 \mathrm{U} / \mu \mathrm{l}$ mung bean nuclease for $30 \mathrm{~min}$ at $37^{\circ} \mathrm{C}$; the DNA was extracted with phenol and chloroform, precipitated, and self ligated for $12 \mathrm{~h}$ at $12^{\circ} \mathrm{C}$ using $5 \mathrm{U}$ of T4 DNA ligase in a volume of $200 \mu \mathrm{l}$. Transformation of competent $\mathrm{DH} 5 \alpha$ cells and selection for ampicillin resistance conferred by the coamplified pcDX vector yielded over 1000 colonies. The sequence of the full-length rabbit muscle cDNA was determined using a T7 sequencing kit (Pharmacia). To exclude any PCR cloning artifacts, rabbit SLN CDNA was also amplified with two oligonucleotides, RSAF 7 and RSAR8 (Table 1 ), using the pcDX library as a template. The sequence of the 0.7$\mathrm{kb}$ product was verified by cycle sequencing.

Cloning of human SLN CDNA. The $3^{\prime}$ end of the human SLN CDNA was cloned by application of the 3' RACE technique (Innis et al., 1990) in which $5 \mu \mathrm{g}$ of total RNA from human skeletal muscle was reverse transcribed with primer RACE 1 (Table 1) as described above. Subsequent PCR amplification with primers RACE 3 and HSAF 1 using Taq polymerase:Pfu polymerase (5:1 ratio) yielded a single product of $550 \mathrm{bp}$, which was cleaved with BamHI and cloned into the Bluescript vector. Sequence analysis indicated that all eight clones analyzed were identical. The $5^{\prime}$ end of human SLN CDNA was cloned by PCR amplification from a $\lambda$ gt11 $5^{\prime}$ stretch CDNA library, kindly provided to us by Drs. Peter Ray and Perry Howard, Hospital for Sick Children, Toronto. Phage DNA was prepared according to the $\lambda$ phage library protocol from Stratagene, in which $1 \mu \mathrm{g}$ of $\lambda \mathrm{gt} 11$ DNA is cleaved by BsiWI (which cuts at both sides of the cDNA inserts) and self ligated. An aliquot con- taining 50 ng of circularized BsiWI DNA was used as a template in an inverse PCR amplification with primers SALF 10 and SALR10 (Table 1). The PCR product of $1.1 \mathrm{~kb}$ was cleaved with BamHI, cloned into Bluescript, and the sequence of the $5^{\prime}$ end of human SLN CDNA was determined. All eight clones analyzed started at the $A$ residue at position +6 of the CDNA sequence (Figs. $1 B$ and 2). In addition, CDNA was reamplified with primers HSAF 5 and HSAR5 from human first-strand CDNA, and the sequence of the 0.7-kb product was verified by cycle sequencing.

Determination of the human SLN genestructure. Two primers at both ends of the full-length CDNA (HSAF5 and HSAR5) were used to amplify human genomic DNA. A single DNA product of $4.5 \mathrm{~kb}$ with a single intron in the $5^{\prime}$ untranslated region of the CDNA was obtained. Flanking genomic DNA sequences were obtained by inverse $\mathrm{PCR}$, in which $4 \mu \mathrm{g}$ of human genomic DNA was cleaved with EcoRI, BglII, or HindlII, extracted with phenol and chloroform, precipitated with 50\% isopropanol containing $250 \mathrm{mM}$ sodium acetate, washed once with $70 \%$ ethanol, and self ligated. The inverse long PCR amplification used $50 \mathrm{ng}$ of circularized DNA with a primer pair corresponding to the 5' (HSAF8, HSAR8) or the 3' (HSAF 1, HSAR1) segments of the CDNA, respectively. For the $3^{\prime}$ end, single products of 5.7 and $3.5 \mathrm{~kb}$ were obtained from the Bglll and Hindl II circularized genomic DNA fragments, but no product was observed when EcoRI circularized DNA was used as a template. For the 5' region, 5-, 4-, and 0.9-kb products were obtained for BgllI, HindlII, and $E$ coRI, respectively (Fig. 1A).

Primer extension. Total RNA was isolated from normal human skeletal muscle of two unrelated individuals as described above. The oligonucleotides HSAR8 or HPE 1 (Table 1) were labeled with polynucleotide kinase and [ $\left.\gamma-{ }^{32} \mathrm{P}\right]$ ATP to a specific activity of $300 \mathrm{nCi} / \mathrm{ng}$. Thirty micrograms of total RNA in $30 \mu$ l of hybridization buffer (40 $\mathrm{mM}$ Pipes (1,4-piperazine-diethanesulfonic acid), $\mathrm{pH} 6.4,1 \mathrm{mM}$ EDTA, $0.4 \mathrm{M} \mathrm{NaCl}, 80 \%$ formamide) was denatured for $5 \mathrm{~min}$ at $90^{\circ} \mathrm{C}$ and annealed overnight at $30^{\circ} \mathrm{C}$ with $3 \mathrm{ng}$ of the labeled oligonucleotide. The nucleic acids were ethanol precipitated, washed, and reverse transcribed as described above. The final pellet was dissolved in $4 \mu \mathrm{l}$ of water, and $6 \mu \mathrm{l}$ of formamide loading buffer was added. 
Three microliters of the product, corresponding to $10 \mu \mathrm{g}$ of reverse transcribed total RNA, was analyzed by electrophoresis on a $7.2 \%$ denaturing polyacrylamide sequencing gel.

Northern blots. Northern blots, containing $8 \mu \mathrm{g}$ of total RNA from rabbit fast-twitch (psoas) and slow-twitch (soleus) skeletal muscle, were prepared and treated as described by Ausubel et al. (1994). Multiple tissue Northern (MTN) blots, loaded with $2 \mu \mathrm{g}$ per lane of poly $(A)^{+}$RNA derived from a number of human tissues, were purchased from Clontech. A gel-purified, 0.5-kb PCR fragment amplified with primers HSAF 1 and HSAR5 from human CDNA and a 2-kb human $\beta$-actin CDNA probe (Clontech) were labeled with $\left[{ }^{32} \mathrm{P}\right] \mathrm{dCTP}$ using random primers and T7 polymerase. Hybridization was carried out for $1 \mathrm{~h}$ at $68^{\circ} \mathrm{C}$ using ExpressHyb solution (Clontech) containing the labeled probe at a final concentration of $5 \mathrm{ng} / \mathrm{ml}\left(1 \times 10^{6} \mathrm{CPM} /\right.$ $\mathrm{ml}$ ). The MTN blots were subjected to autoradiography for 2,16 , and $72 \mathrm{~h}$, at $-70^{\circ} \mathrm{C}$ using Kodak $\beta$-max film and two intensifying screens. The blots were stripped and probed for $\beta$-actin mRNA according to the protocol of the manufacturer. Autoradiography was for $4 \mathrm{~h}$.

Southern blots. Multiple species Southern (Zoo) blots, loaded with $4 \mu \mathrm{g}$ of genomic DNA cleaved with the restriction endonuclease EcoRI, were purchased from Clontech and hybridized according to the instructions of the manufacturer. Either the 0.5-kb HSAF 1HSAR5 probe, specific for exon 2 (described above), or the 350-bp probe obtained with primers HSAF 12 and HSAR8, specific for the $5^{\prime}$ region of the SLN gene, was used. The blot was washed at low stringency $\left(2 \times \mathrm{SSC}, 0.05 \% \mathrm{SDS} ; 60^{\circ} \mathrm{C}\right)$.

Chromosomal mapping of the SLN gene To determine the chromosomal localization of the SLN gene, a 4.5-kb, PCR-amplified genomic DNA fragment (HSAF 5 and HSAR5) was used for fluorescence in situ hybridization (FISH) experiments. FISH was performed following the procedure of Lichter et al. (1990), by counterstaining the chromosomes with propidium iodide and DAPI. The biotinylated probe was detected with avidin-FITC. I mages of metaphase preparations were captured by a thermoelectrically cooled, charge-coupled camera (Photometrics, Tucson, AZ). Separate images of DAPIbanded chromosomes (Heng and Tsui, 1993) and of FITC-targeted chromosomes were obtained. Hybridization signals, pseudocolored yellow for FITC and pseudocolored blue for DAPI-stained chromosomes, were overlaid electronically and merged using Adobe Photoshop 3.0 software. The band assignment was determined by measuring the fractional chromosome length and by analyzing the banding pattern generated by the DAPI counterstained image.

The chromosomal localization of the SLN gene was confirmed by screening the NIGMS somatic cell hybrid panel 2 (Dubois and Naylor, 1993) and the GeneBridge 4 radiation hybrid $(\mathrm{RH})$ panel (Walter et al., 1994), purchased from Research Genetics. Radiation hybrid mapping experiments were carried out in duplicate and the data were analyzed at a lod score of $>3.0$ using the RH server from the Whitehead Institute/MIT Center for Genomic Research. The primers used for this specific analysis were HSAF9 and HSAR11 (Table 1), which amplified a 900-bp human-specific band using the following conditions: denaturation at $94^{\circ} \mathrm{C}$ for $30 \mathrm{~s}$; annealing at $62^{\circ} \mathrm{C}$ for $2 \mathrm{~min}$; extension at $72^{\circ} \mathrm{C}$ for $2 \mathrm{~min}$, for 35 cycles. The complete set of $\mathrm{RH}$ data is available through the NCBI radiation hybrid mapping service at http://www.ncbi.nlm.gov/SCIENCE 96/.

Analysis of mutations in ATP2A1 of patients from Brody families BD3 and BD6. Genomic DNA was amplified, and the 23 ATP2A1 exons, plus 1500 bp upstream of the transcription initiation site containing the putative promoter region, were sequenced, as described by Odermatt et al. (1996). At least 30 bp of flanking sequence was determined for each exon.

Analysis of SLN sequence in patients of Brody families BD3 (F3) to BD7 (F 7). Muscle biopsies were available from Brody patients F4P3 and F5P3 (Table 2). First-strand CDNA, prepared as described above, was amplified with primers HSAF 5 and HSAR5, and the sequence of the $0.7-\mathrm{kb}$ product was determined by cycle sequencing. Genomic DNA was isolated from blood from patients F 3P3, F6P3, and F 7P3, using the Qiaamp blood kit (Qiagen). A 5-kb DNA fragment was amplified with primers HSAF 12 and HSAR 11. PCR ampli-
A
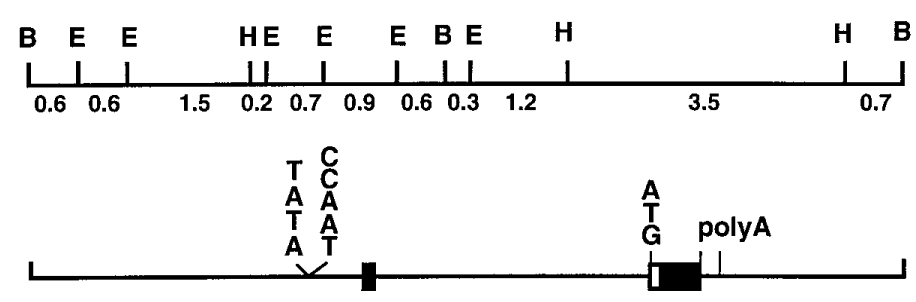

FIG. 1. (A) Structure and restriction map of human SLN. The upper line shows the restriction endonuclease map of the gene derived from clones obtained by PCR amplification. Restriction endonuclease sites are: $\mathrm{E}, \mathrm{EcoRI} ; \mathrm{B}, \mathrm{BglII} ; \mathrm{H}$, HindlII. The locations of the two exons within the gene (solid boxes) and the location of the coding sequence within exon 2 (white box) are indicated on the lower line. The positions of the TATA and CCAAT sequences, the ATG initiation codon, and polyadenylation signal sequences are marked. (B) Nucleotide and deduced amino acid sequences of human SLN. Upstream nucleotides, in lowercase, are numbered negatively, on the left, to thetranscription initiation site. Exon sequences are in uppercase and numbered positively thereafter. The sequence of the single intron is presented in lowercase and is not numbered. Numbers relative to the CDNA at the ends of both exons are in parentheses below the sequence. Putative DNA binding elements for eukaryotic transcriptional factors are underlined and identified bel ow the sequence. The GenBank accession number for these sequences are U96092U96094.

fication and cycle sequencing were performed as described by Odermatt et al. (1996).

Case histories. Brody patients F 3P3, F4P3, and F5P3 were described as patients 1- 3 in Zhang et al. (1995). Patient F 3P3 was also described as patient 1 in Karpati et al. (1986). Patient F6P3 had a long history of exercise and cold-induced muscle stiffness, pain, and cramps. Treatment with Verapamil produced impressive improvement in his symptoms. His mother and sister were said to suffer from similar symptoms, suggesting dominant inheritance of the disease. No myotonia was observed either clinically or on electrophysiological testing. Creatine kinase was mildly elevated. Ischemic exercise testing showed normal elevation of serum lactate and ammonia. A muscle biopsy showed nonspecific, mixed myopathic and neuropathic features. Patient F 7P3 was described as patient 6 in Benders et al. (1994).

\section{RESULTS}

\section{Characterization of the Human SLN Gene}

Figure $1 \mathrm{~A}$ shows the structure and restriction map of human SLN, and Fig. 1B provides a partial DNA sequence of the human SLN gene. The partial sequence includes: $967 \mathrm{bp}$ of the $5^{\prime}$ region containing the probable promoter of the SLN gene, nuceotides -967 to -1 ; exon 1 nucleotides +1 to +99 , which form part of the $5^{\prime}$ untranslated region of the CDNA; about $300 \mathrm{bp}$ of sequence at both the $5^{\prime}$ and the $3^{\prime}$ ends of the single 3.9-kb intron; exon 2 nucleotides +100 to +719 , which form the remainder of the $5^{\prime}$ untranslated region, the coding sequence for SLN, and the 3' untranslated region of the SLN gene; and 556 bp of downstream sequence. Primer extension analysis using total RNA isolated from skeletal muscle of an individual with no 
-967 agatttcctctattattctataaagaaaggatctgctgagcaaacacaattgcatgggtc TATA

-907 atgtttaaagtacttaattgatctgcttcaagtctaatttaacacttcaggggatccaa -847 acatgtgatacttggttacaaactcatctagtctaattttagttagtgttcatattaga $\mathrm{E}$ MEF 3-1ike $\mathrm{MEF} 2$ -787 aagttatataatactttcttcttcagatatattctataattcacattttcactaat TATA

-727 tttacccagttctccttccactcccaatctatccaaataactgagttgaactgtgtgagt -667 ttactgctctattaattattgccagagatatacaaaccatgacttcctcggctgtttca

-607 gatgaaatgtagatccacgtgtaaacttgcaatgcacagcttagctggaaagttacgtgg $\mathrm{E} \quad 11 \mathrm{bp} \quad \mathrm{E}$

-547 agcaggtgacggaggggatagcttcactgcttggacaaagtcagttttgaaagagctaa $\mathrm{E}$ MEF3-1ike

-487 agatgcctattgaattctggagtgtgtgtgtgtgtgtatgggtgtgcatatgtgtgggtg ECORI $\mathrm{E}$

-427 taaggcagcaaactcttcacatttcaaataactaaagatatgggtggtaaaatgaagtca

-367 cattttacacctcacaggctoactacggagagcagtcaaatgcagcatcgattggttaa

-307 aattagtctatcattcttggtttatgatgttttaaagacatgttaaagttattcatgaag

-247 atgtaaagacacatttaaacccacatcaattgcactaaaagtcaactggaaacagaag E $10 \mathrm{bp}$ $\mathrm{E}$

-187 gttttaaatcctggtggtggcaaattggcagccaaaggaacaaagtcttagtcaacata -127 tttccatgtcccccgaacacaaatagcctcgaaccttcggagggtgttcctttgagatgt

-67 ttcatcagtgacatcacagtgattgccagcttccacggactactttaggcgctgcccaga

-7 gtccagg/AGTCCAGACAGCCTGGGAGGGGAGAAGGAGTTGGAGCTCAAGTTGGAGACAG $(+1)$

+53 CGAGGAGAAACCTGCCATAGCCAGGGTGTGTCTTTGATCCTCTTCAG/gtaactgcagga $(+99)$

tttttatgcttagcatacggtgtgtgtgtgtgtacaagctgcaaatgagaaaggcagagg aatgtt tgcatt tct taatgaaataggcaatgccctggatacagcatgcct aagatat aagtgagtactattgcttetgtttccttttttctcctaagggtatgcatttct ccctcctagtaaaaaaaattttttcctttctgtattatggaagatggtctttttc tatcttctctaagtctccattcaaagaaagccaatgtcaaacttcctgcacatttattca gagcttttt.... $3.3 \mathrm{~kb}$
tccttaattacctaattttaacttatttacctcttaaagaccctatcttcaaacacagt cacattctgagatactgtgagctagggctttgacatgtagatttttgggggacacaatt agcccatcacactctcctttccacaacacttctgtttcctttgaggaaagaacgggcat

tgttatacaggaatgcccattaatctccttgtgttttcttgttatgttttatcag/GAG $(+100)$ GTGAGGACAAGCCAGAGGTCCTTGGTGTGCCCTCAGAAATCTGCCTGCAGTTCTCACCAA GCCGCTGTGAAAATGGGGATAAACACCCGGGAGCTGTTTCTCAACTTCACTATTGTCTTG MetGlyIleAsnThrArgGiuLeuPheLeuAsnPheThrIleVal Leu ATTACGGTTATTCTTATGTGGCTCCTTGTGAGGTCCTATCAGTACTGAGAGGCCATGCCA

II ThrVal I l eL euMe t Trp Le ULeUValArgSerTyrGinTyr * * *
TGGTCCTGGGATGACTGAGATGCTCCGGAGCTGCCTGCTCTATGCCCTGAGACCCCACT GCTGTCATTGTCACAGGATGCCATTCTCCATCCGAGGGCACCTGTGACCTGCACTCACAA

TATCTGCTATGCTGTAGTGCTAGGATTGATTATGTGTTCTCCAAAGATGCTGCTCCCAAG GGCTGCCAAGTGTTTGCCAGGGAACGGTAGATTTATTCCCCAACTCTTAACTGAAAATGT MRNA degradation

GTTAGACAAGCCACAAAGTTAAAATTAAACTGGATTCATGATGATGTAGGATTGTTACAA putative poly (A) ${ }^{+}$

GCCCCTGATCTGTCTCACCACACATCCCTTCAACCCACACGGTCTGCAACCAAACTCTAA

\begin{abstract}
TTCAACCTGCCAGAAGGAATGTTAGAGGAAGTCTTTGTCAGCCCTTATAGCTATCATGTG
\end{abstract}
AATAAAGTTAAGTCAACTT/caaaaacaacttctagaacttattttagcttccatgtgtg poly $(\mathrm{A}){ }^{+}(+719)$

acagagcatttgacccttggctgggattggagtgacaagtgctaccgtatttctagcatt tgaggtaagccaagatgctccaactgctgaagatttgaaaccaagtcaacacactgtgtc atattcaagtaattccattggttcagcgctcctcaaactttcccctaaltagtctga agggcagagggagaataaatccattccactacggggtctgaagcacaggctgaattgctg poly $(A)+$

gctaaaagtgcaacatttcttgaagtcttgtgttttatctttagaatccacaagaaatg tatttctatcttataatatcttcatgtttgtttcatataaatattaaattatttac actaagtadcacaagaacatgagtcatgtccctaagagtagcatagtctatttgattat tgttattacacaaatggagctagtctttaatcaactacagttctaaaaggaggaaaatag aaatgcaaacttatatgtttataaagacatataa

FIG. 1-Continued

history of genetic disease was carried out to determine the transcription initiation site. A single product was generated using primer HSAR8 (complementary to a sequence within exon 1; Fig. 2) or HPE 1 (complementary to a sequence within exon 2; not shown). The SLN transcription initiation site was assigned to an A residue 175 bases upstream from the translation initiation site in mRNA (+1 in Figs. 1B and 2$)$. The polyadenylation site in the major transcript was located at nucleo- tide +719 in Fig. 1B. The total length of the gene is about $5.6 \mathrm{~kb}$.

A search for potential DNA binding elements for known eukaryotic transcriptional factors revealed a cluster of three possible TATA box sequences between -745 bp and -783 bp (Fig. 1B). Two additional TATA boxes were found between -945 and -949 bp and between -633 and -636 bp. A CCAAT box was found 45 bp downstream of the TATA box cluster between -700 and $-704 \mathrm{bp}$. The CCAAT box of the SLN gene, CTCCCAATCT, differed from the consensus sequence GGY CCAATCT (Lewin, 1994) in having pyrimidines rather than purines upstream of the YCCAATCT sequence. Several E box sequences (CANNTG), recognized by the MyoD family of basic helix-loop-helix transcriptional activators (Piette et al., 1990; Weintraub et al., 1990), were identified in the $5^{\prime}$ region of the SLN gene. One pair of $E$ boxes, separated by 11 bp and lying between -587 and $-609 \mathrm{bp}$, and a second pair of E boxes, separated by $10 \mathrm{bp}$ and lying between -198 and $-219 \mathrm{bp}$, were located downstream of the CCAAT box. In addition, a potential binding site for the myocyte enhancer factor MEF-2 (CTA $(A / T)_{4}$ TAG) was identified upstream of the TATA box cluster between -805 and $-814 \mathrm{bp}$. The sequence CTTGGTTACAA, with similarity to the MEF-3 enhancer element (TCAGGTTT(T/A)CA) described by Hidaka et al. (1993), was found just upstream of the MEF-2 motif between -828 and -838 bp. An additional MEF-3-like motif (TCAGTTTTGAA) was found between -497 and $-505 \mathrm{bp}$. Unlike the MEF-3 consensus sequence, the motifs found in the SLN gene had palindromic ends. We identified a possible site for the transcriptional activator protein AP-

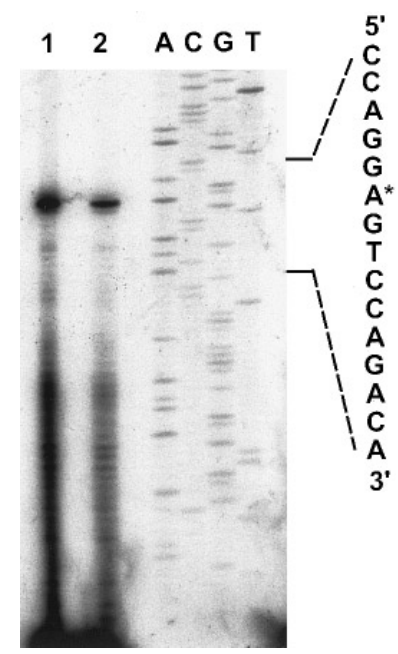

FIG. 2. Primer extension. $10 \mu \mathrm{g}$ of total RNA from normal human skeletal muscle of control individuals 1 (lane 1) or 2 (lane 2) were reverse transcribed using ${ }^{32} \mathrm{P}$-labeled oligonucleotide HSAR8. (A, C, $\mathbf{G}, \mathbf{T})$ Sanger sequencing reactions with the same primer. The reaction products were resolved on a $7.2 \%$ DNA sequencing gel, and radioactivity was visualized by autoradiography. The relevant DNA sequence is given on the right. The transcription initiation site is indicated by an asterisk. 


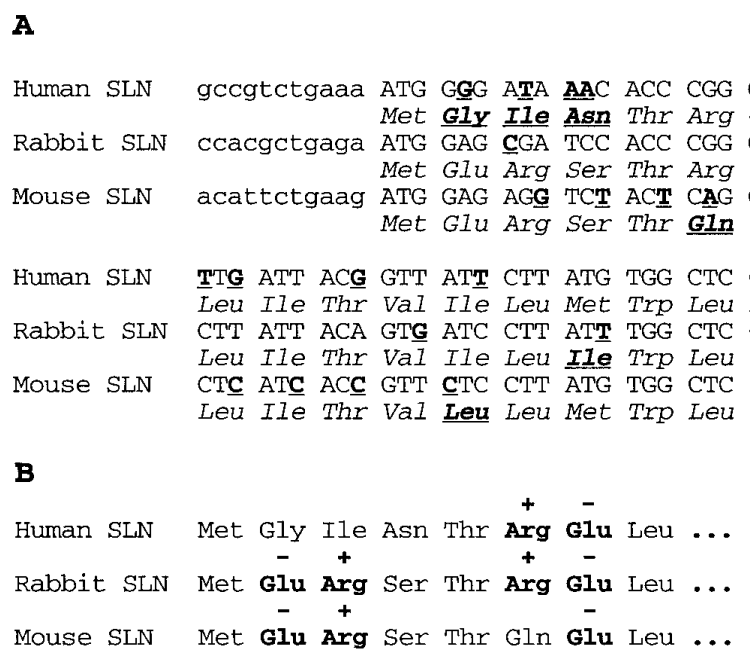

FIG. 3. (A) Alignment of human, rabbit, and mouse SLN nucleotide and deduced amino acid sequences. The first 11 nucleotides, in lowercase, form part of the translation initiation sequence (Kozak, 1987), while the nucleotides in uppercase indicate coding sequences. Stop codons are italicized. Nucleotides and amino acids deviating from the consensus sequence are underlined and boldface. (B) Comparison of charge distribution in the hydrophilic, N-terminal domain of human, rabbit, and mouse SLN.

1 (Lee et al., 1987) between -341 and -348 bp. The translation initiation signal sequence (Kozak, 1987) at the end of the promoter sequence (GCTGTGAAAATGG) is reasonably conserved compared to the consensus sequence (GCCGCCA/GCCATGG).

Sequencing of the $3^{\prime}$ end of the human SLN gene revealed the major polyadenylation signal, AATAAA, between nucleotides 701 and 706, with polyadenylation occurring after residue 719. A potential polyadenylation signal sequence, AATAAA, was also found 252 bp downstream of the major polyadenylation signal sequence. To test whether this downstream polyadenylational signal was used, PCR analysis was carried out with a forward primer (HSAF 3 ) in exon 1 and a reverse primer (HSAR 11) at the downstream poly $(A)^{+}$site. Human skeletal muscle first-strand CDNA primed with oligo(dT) was used as a template. A product of $660 \mathrm{bp}$ was amplified (not shown), indicating that the longer transcript was, indeed, synthesized. Contamination by genomic DNA was excluded on the basis of the absence of intronic sequence in the PCR product. We estimate that the level of the longer transcript was less than $5 \%$ of that of the major 719-bp transcript. There was no indication of the use of a potential polyadenylation signal sequence, AATTAA, 158 bp upstream of the major signal sequence.

\section{I solation and Analysis of CDNA Clones Encoding Rabbit and Human SLN}

Nucleotide sequence. Figure 3 illustrates the nucleotide sequences encoding human, rabbit, and mouse SLN and their deduced amino acid sequences. The rabbit sequences were confirmed in eight clones obtained from a CDNA library by circularization, following inverse long PCR amplification from primers in exon 2.
The human sequences were obtained by similar methods, as outlined under Materials and Methods. Sequences from mouse cardiac and skel etal muscle SLN were obtained from a computer search of the GenBank EST database, which also identified human SLN EST sequences (Washington University School of MedicineMerck EST project) covering most of the full-length CDNA, but lacking the 5' and 3' tails.

Comparison of human, rabbit, and mouse SLN cDNAs revealed $84 \%$ nucleotide sequence identity between human and rabbit, $44 \%$ nucleotide sequence identity between human and mouse, and $41 \%$ nucleotide sequence identity between mouse and rabbit SLN cDNAs. The higher level of nucleotide sequence identity between the human and rabbit SLN CDNAs is reflected in their identical length and in their use of the same polyadenylation signal sequence for the major transcript, $14 \mathrm{bp}$ upstream of the poly $(\mathrm{A})^{+}$tail. This polyadenylation site is lacking in the mouse SLN ESTs, which contain a consensus polyadenylation signal sequence 150 bp further downstream, with polyadenylation occurring an additional 100 bp downstream. The length of the mouse SLN cDNA is at least $950 \mathrm{bp}$. An AUUUA motif that could act as an RNA degradation signal (Shaw and Kamen, 1986) is present in the major transcript of human and rabbit mRNA, about 250 bp downstream of the stop codon, but is lacking in the mouse transcript. Another potential polyadenylation signal sequence, present in all three species, is located $50 \mathrm{bp}$ downstream of the potential RNA degradation signal. The first 11 nucleotides, which include the translation initiation signal sequence (Kozak, 1987), are not well conserved among the three species.

Amino acid sequence. The SLN gene encodes a protein of 31 amino acids that can be divided into three 


\section{$\mathbf{N}$ \\ . QARQKLQNLFINFCIILICLLLICIIVMLL \\ $:::||:||::||:: \mid:::$ : \\ MGINTRELFLNFTIVLITVILMWLLVRSYQY \\ ERS $Q{ }^{*} C I \quad V \quad I I$ \\ Human PLN \\ Human SLN}

FIG. 4. Alignment of human SLN and PLN peptide sequences. Amino acids 23 to 52 of human PLN are shown in the upper line. The lysine at position 27 of human PLN is replaced by an asparagine in PLN of rabbit, dog, and pig (above). The peptide sequence of human SLN is shown in the lower line. Amino acids different in rabbit or mouse are indicated beneath. The vertical lines in the alignment indicate identical amino acids, whereas conserved amino acids are shown by two vertical dots. The asterisk indicates the first and last amino acid of the predicted transmembrane helix of SLN.

domains: a hydrophilic $\mathrm{N}$-terminal domain of 7 amino acids; a hydrophobic, transmembrane helical domain of 19 amino acids; and a hydrophilic C-terminal domain consisting of 5 amino acids. Neither the hydrophilic Nterminal sequences nor the hydrophobic transmembrane sequences are well conserved among the three species studied, and changes in net charge occur in the $\mathrm{N}$-terminal sequences. The hydrophilic C-terminal sequences are, however, perfectly conserved. The amino acid sequence of the rabbit protein, deduced from the CDNA, is identical to the peptide sequence determined by Wawrzynow et al. (1992).

The SLN sequence from residue 4 to residue 26 (4 $\mathrm{N}$-terminal hydrophilic residues and 19 hydrophobic transmembrane residues) shares a striking similarity with residues 28 to 49 of PLN (Fig. 4). This similarity becomes more evident if alternate residues at different points in the sequences of the three species are considered. $\mathrm{Asn}^{4}$ in human SLN corresponds to $\mathrm{Asn}^{27}$ in PLN in rabbit, pig, and dog. GIn ${ }^{6}$ in mouse SLN corresponds to $\mathrm{GIn}^{29}$ in human PLN. At human SLN positions 10, 20, and $22 \mathrm{Leu}$, Ile, and Met differ from the corresponding residue in human PLN, but in other species, correspondence of one or more of these residues is observed. On the basis of these sequence similarities, we propose that SLN and PLN are homologous proteins. Since the orientation of PLN in the membrane is well established, we propose that the N-terminal domain of SLN is cytosolic and that the C-terminal domain faces the lumen of the sarcoplasmic reticulum.

\section{Characterization of SLN Expression}

The distribution of SLN mRNA in various human tissues was determined by Northern blot analysis using a PCR-amplified probe from the $3^{\prime}$ untranslated region of the cDNA that hybridized to a single transcript of $0.7 \mathrm{~kb}$ (Fig. 5). This SLN transcript was highly expressed in skeletal muscle, but was at least 50-fold less abundant in heart muscle, as determined by densitometry of the exposed film. Only trace amounts were detected in prostate and pancreas. In all other tissues analyzed (brain, placenta, lung, liver, kidney, uterus, colon, small intestine, bladder, and stomach), no SLN transcript was detected. A 9-fold higher level of the
SLN transcript was found in rabbit fast-twitch skeletal muscle (psoas) than in slow-twitch skeletal muscle (soleus) (Fig. 5C).

\section{Multiple-Species Genomic DNA Analysis}

A Southern blot containing genomic DNA from nine eukaryotic species, digested with restriction endonuclease EcoRI, was probed with a 350-bp, PCR-amplified DNA fragment from the 5' exon 1-containing region of the SLN gene (Fig. 6). A single band was detected in genomic DNA from each of human $(0.9 \mathrm{~kb})$, monkey (0.95 kb), dog (1.5 kb), cow (1.05 kb), and rabbit (4.4 $\mathrm{kb})$. The size of $0.9 \mathrm{~kb}$ of the EcoRI-digested human genomic DNA fragment confirmed the finding of a 0.9kb DNA product obtained by inverse PCR amplification with primers specific for the 5' region of the SLN gene. Genomic DNA from chicken yielded two bands of 1.6 and $2.6 \mathrm{~kb}$. The hybridization signal of the human probe with mouse and rat genomic DNA was very weak, reflecting the fact that there is much lower similarity between human and mouse SLN CDNAs than between human and rabbit SLN CDNAs. No hybridization to digested yeast genomic DNA was observed. A similar pattern was obtained using a labeled probe specific for the $3^{\prime}$ region of the SLN gene (not shown).

\section{Chromosomal Localization}

To determine the location of the SLN gene, we performed FISH using a 4.5-kb, PCR-amplified DNA probe covering both exons and the single intron. Positive signals were observed on both chromosome 11 chromatids in the region of 11q22-q23. No hybridization to any other chromosome was observed. The assignment of the SLN gene to human chromosome 11 was confirmed using monochromosomal rodent-human somatic cell hybrids. To refinethe position of the gene on the genetic and physical map of 11q, we screened the GeneBridge $4 \mathrm{RH}$ panel. The results indicate that SLN is flanked by the two genetic markers CHLC.GATAGC11 and CHLC.GATA71E 06. SLN was $7.04 \mathrm{cR}$ from the former marker. Although this entire region appears to be covered by a set of overlapping YACs (Hudson et al ., 1995), our analysis failed to detect a positive clone for the SLN gene from this collection. Nevertheless, the FISH and $\mathrm{RH}$ data are consistent, indicating that the gene maps to human chromosome 11q22- q23.

\section{Sequencing of SLN from Patients of Brody Families} BD3 to BD7

No mutations were found in the sequence of the SLN CDNA amplified from patients F4P3 (recessive inheritance, Table 2) or F5P3 (dominant inheritance), nor were any mutations found in the sequence of the SLN gene amplified from genomic DNA from patients from families BD3 (recessive), BD6 (dominant), or BD7 (dominant) (Table 2). Genomic sequences included each of the two exons 
A

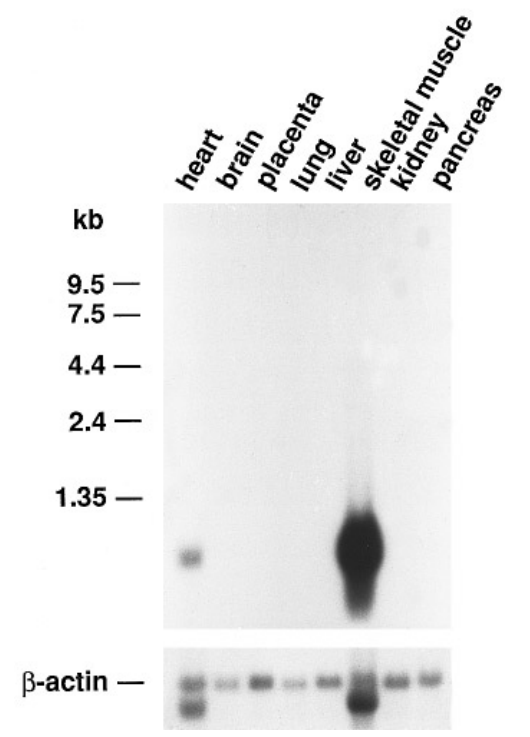

B

kb

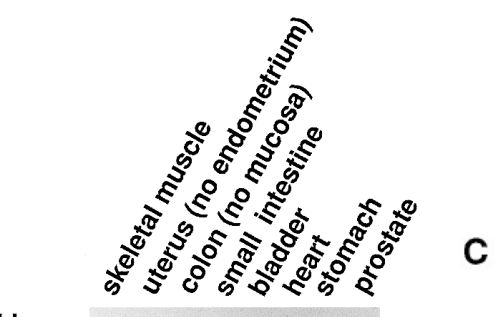

C

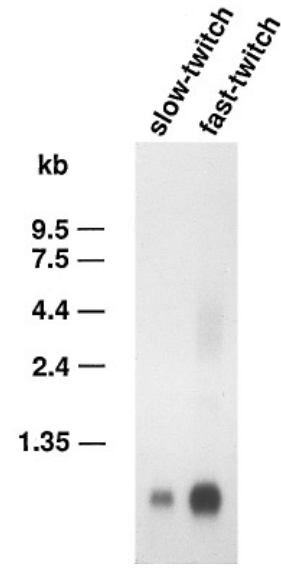

FIG. 5. Analysis of SLN gene expression. Human multiple tissue Northern (MTN) blots (Clontech) containing: (A) mRNA from heart, brain, placenta, lung, liver, skeletal muscle, kidney, and pancreas; and; (B) skeletal muscle, uterus (no endometrium), colon (no mucosa), small intestine, bladder, heart, stomach and prostate (top) were probed with a 0.5-kb PCR product (HSAF 1- HSAR5) derived from human SLN cDNA. The positions of RNA size markers $(\mathrm{kb})$ are indicated on the left. Autoradiography was carried out for $16 \mathrm{~h}$ at $-70^{\circ} \mathrm{C}$. (Bottom) The same blots were probed with a human $\beta$-actin cDNA and exposed for $4 \mathrm{~h}$. The second hybridization signal at $1.6-1.8 \mathrm{~kb}$ observed in both heart and skeletal muscle is due to probe hybridization to either the $\alpha$ or the $\gamma$ form of actin (Giovanna et al., 1991; Lamballe et al., 1991). (C) Analysis of SLN expression in rabbit fast-twitch and slow-twitch skeletal muscle. The Northern blot was probed with the 0.7kb RSAF 7-RSAR8 PCR product, specific for rabbit SLN mRNA. Autoradiography was for $6 \mathrm{~h}$.

and at least $100 \mathrm{bp}$ of intron sequence flanking each exon and $850 \mathrm{bp}$ of the proposed promoter region. The substitution of $\mathrm{G}$ for $\mathrm{C} 11$ in the $5^{\prime}$ untranslated region of exon 2 was detected in patient F3P3. The insertion of a T in both alleles at position -118 was observed in patient F6P3. This mutation did not affect the structure of SLN and was not considered significant.

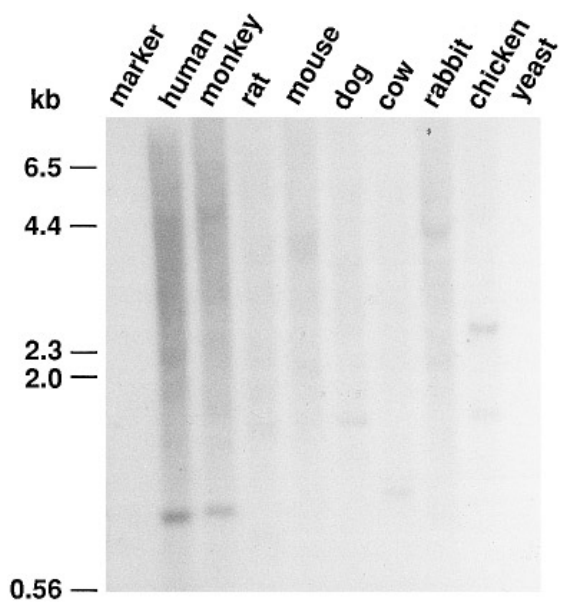

FIG. 6. Southern blot analysis of the SLN gene. A multiple species Southern bl ot (Clontech) was probed with the 350 bp HSAF 12HSAR8 PCR product, specific for the 5' region of the human SLN gene, and washed under low-stringency conditions $\left(60^{\circ} \mathrm{C}: 2 \times \mathrm{SSC}\right.$, $0.05 \%$ SDS). Positions of DNA size markers are indicated on the left.

\section{Sequencing of ATP2A1 from Genomic DNA of} Patients F $3 P 3$ and F6P3

Sequence analysis of ATP2A1 from genomic DNA of patient F6P3 (dominant) did not reveal any mutations in the putative promoter region, in the two exons, or in 10-100 bp of intronic sequence flanking each exon. The substitution of $T$ for $C 678$, a polymorphism that does not change the amino acid sequence (Zhang et al., 1995), was detected in patient F6P3.

The fact that no detectable defect in either SLN or ATP2A1 (Zhang \& al., 1995) had been found in patient F 3P3 (recessive), who had been reported to be devoid of SERCA1 (Karpati \& al., 1986), led us to a reexamination of ATP2A1 in this patient and his brother (patient 2 in Karpati et al., 1986). Haplotyping of the region surrounding ATP2A1 as described by Odermatt et al. (1996) showed that these brothers had the identical haplotype on both chromosomes, indicating homozygosity in this region (not shown). The fact that the parents in this family were first cousins is consistent with this degree of homozygosity.

Resequencing of ATP2A1 from patient F 3P3 showed the presence of the T for C678 polymorphism noted earlier (Zhang et al., 1995), but this time the deletion of a $C$ in a series of three Cs (CDNA nucleotides 437 to 439) was detected (Fig. 7). This deletion led to a homozygous frame shift at $\mathrm{Pro}^{147}$, which would lead to a stop codon in both transcripts after the incorporation 
TABLE 2

Analysis for Mutations in ATP2A1 and SLN of Brody Families

\begin{tabular}{|c|c|c|c|c|c|}
\hline Family & Patient & ATP2A1 & SLN & Inheritance & Reference \\
\hline BD1 & F1P3, F1P4 & Homozygous Arg $^{198}$ to Stop & n. d. & Recessive & $\mathrm{F} 1 \mathrm{P} 3{ }^{\mathrm{a}} \mathrm{P} 4^{\mathrm{b}}$ \\
\hline $\mathrm{BD} 2$ & $\begin{array}{l}(\mathrm{F} 2 \mathrm{P} 1),{ }^{c} \mathrm{~F} 2 \mathrm{P} 3, \mathrm{~F} 2 \mathrm{P} 4 \\
(\mathrm{~F} 2 \mathrm{P} 2),{ }^{\mathrm{e}} \mathrm{F} 2 \mathrm{P} 3, \mathrm{~F} 2 \mathrm{P} 4\end{array}$ & $\begin{array}{l}\text { Cys }{ }^{675} \text { to Stop, and intron } \\
3 \text { splice donor GT to CT } \\
\text { (compound heterozygote }\end{array}$ & n. d. & Recessive & $\mathrm{F} 2 \mathrm{P}{ }^{\mathrm{a}}{ }^{\mathrm{P}} 3^{\mathrm{d}}$ \\
\hline BD3 & F 3P3, F 3P4 & $\begin{array}{l}\text { Homozygous deletion of a C } \\
\text { frameshift at } \text { Pro }^{147}\end{array}$ & No mutation & Recessive & $\mathrm{P} 1,{ }^{d} \mathrm{P} 1^{f}$ \\
\hline BD4 & F4P3 & No mutation & No mutation & Recessive & $P 2^{f}$ \\
\hline BD5 & F5P3 & No mutation & No mutation & Dominant & $P 3^{f}$ \\
\hline BD6 & F6P3 & No mutation & No mutation & Dominant & \\
\hline BD7 & F7P3 & n. d. & No mutation & Dominant & $P 6^{b}$ \\
\hline
\end{tabular}

${ }^{a}$ Odermatt et al. (1996).

${ }^{\mathrm{b}}$ Benders et al. (1994).

' Unaffected father.

${ }^{\mathrm{d}}$ Karpati et al. (1986).

e Unaffected.

f Zhang et al. (1995).

of 33 additional amino acids. This mutation is very similar to the two cases of ATP2A1-linked Brody disease described earlier (Odermatt et al., 1996) in that mutations in both alleles led to premature termination codons and to truncation of SERCA1. In three of four cases of autosomal recessive inheritance of Brody disease described to date, SERCA1 protein has been lost due to these truncations (Table 2 ). Our results suggest that mutations in ATP2A1, leading to a predicted functional knock-out of SERCA1, account for the majority of autosomal recessive forms of Brody disease, but not for dominant forms of the disease.

\section{DISCUSSION}

Cloning of Rabbit and Human SLN by Application of Inverse Long PCR Several earlier attempts in our laboratory to clone SLN by hybridization screening of a skeletal musclelibrary were unsuccessful, even though the CDNA is present in our pcDX library, as described here, and is present in other libraries from both skeletal and cardiac muscle (Washington School of Medicine- Merck EST project, GenBank). In this study, we cloned the SLN gene from our full-length rabbit skeletal muscle cDNA library in the pcDX vector by a novel application of inverse long PCR. In this method, the vector sequence, containing an antibiotic resistance marker, was coamplified with the full-length cDNA, allowing us to self-ligate the PCR product and use the circularized DNA directly for transformation of competent bacterial cells. Since self-ligation was very efficient, as little as $1 \mathrm{ng}$ of circularized PCR product was sufficient for successful cloning. By inverse long PCR, products up to $8 \mathrm{~kb}$ in length have been obtained. Accordingly, this method has potential application for direct cloning of even very long cDNAs inserted into vectors of the usual length of about $4 \mathrm{~kb}$. For example, we have successfully cloned full-length ATP2A1 CDNAs of

\section{BD3}

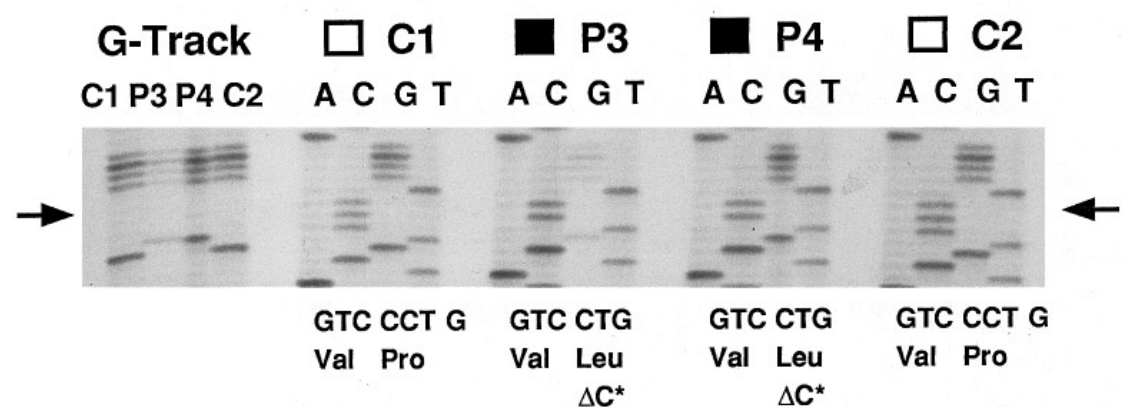

FIG. 7. Analysis of the deletion of one of the three Cs in nucleotide positions 437, 438, and 439, numbered according to the cDNA sequence of the ATP2A1 gene encoding SERCA1 (Zhang et al., 1995), in family BD3. PCR amplified ATP2A1 genomic DNA was sequenced, and the deletion of one of the three Cs at Nucleotides 437, 438, or 439, leading to a frameshift beginning with the codon for Pro ${ }^{147}$, is indicated by an arrow. The effect of the mutation on amino acid sequences is shown beneath. The G-track and the nucleotide sequences of the homozygous mutant DNAs of the two affected brothers, F 3P3 and F 3P4, and two unrelated control DNAs, C1 and C2, are indicated. 
$3.5 \mathrm{~kb}$ from our pcDX library. The use of Pfu polymerase to avoid PCR artifacts is strongly recommended.

We also applied inverse long PCR to a human skeletal muscle $5^{\prime}$ stretch cDNA library in $\lambda$ gtll to clone human SLN. The phage DNA was digested with an enzyme flanking the CDNA at both sides, and the circularized DNA was used as a template for inverse long $P C R$. The disadvantage of using phage library templates is the lack of a selectable marker on the amplified product. Accordingly, it is necessary to recover much higher yields of the PCR product for cloning into a plasmid vector.

\section{5' Upstream Region of the Human SLN gene}

In the SLN gene, a cluster of three TATA box elements is located about $40 \mathrm{bp}$ upstream of a CCAAT box, which, in turn, is found 700 bp upstream of our proposed transcriptional start site. A similar unusual arrangement of CCAAT and TATA box elements was described for the skeletal muscle RYR1 gene (Phillips et al., 1996), with a CCAAT sequence 68 bp upstream of the transcription initiation site and a cluster of five TATA box elements a further 1500 bp upstream. A binding site for the myocyte enhancer factor, MEF 2, in combination with a MEF3-like element, follows just upstream of the TATA box cluster in the SLN gene. The muscle-specific induction of the aldolase $A$ gene has been shown to be controlled through cooperation between the muscle-specific factor MEF2 and the more ubiquitous factor MEF 3 (Hidaka et al., 1993). An additonal MEF 3-like site is located 200 bp downstream of the CCAAT box in the SLN gene. The $5^{\prime}$ region of the SLN gene contains several E boxes (CANNTG). E boxes, which are recognized by the MyoD family of basic -helix- loop-helix transcriptional activators, occur by chance every 250 bp in DNA sequences. However, MyoD has been shown to bind cooperatively to paired sites with a 19-bp space in the muscle creatine kinase enhancer (Weintraub et al., 1990) and to paired sites with a 12-bp space in the acetylchol ine receptor $\alpha$-subunit enhancer (Piette et al., 1990). In the SLN gene, two $E$ box pairs with 11 and 10 bp space between both $E$ boxes follow about 200 and 500 bp downstream of the CCAAT box. These DNA binding elements might be responsible for the muscle-specific expression of the SLN gene revealed by Northern analysis. In contrast to the ATP2A1 gene (Korczak et al., 1988) and the RYR1 gene (Phillips et al., 1996), Spl sites and the proposed muscle-specific promoter element GGCTGGGG are absent from the SLN promoter region.

\section{Conservation of SLN in Different Species}

Alignment of amino acid sequences of SLN from human, rabbit, and mouse (this study; Washington School of Medicine-Merck EST project, GenBank; Wawrzynow et al., 1992) revealed poor conservation of the hydrophilic $\mathrm{N}$-terminal sequence, a relatively well-con- served hydrophobic transmembrane sequence, and perfect conservation of the C-terminal hydrophilic sequence, which, by analogy with the well-characterized structure of phospholamban (F ujii et al., 1991), should lie in the lumen of the sarcoplasmic reticulum. The functional consequences of the different charge distribution in the cytoplasmic domain of SLN in thethree species are not clear. By contrast, SE RCA1, with which SLN seems to interact, is highly conserved between rabbit and human (Zhang et al., 1995). The low level of conservation of the SLN CDNA between different species is also reflected in the weak hybridization signal obtained on a Zoo blot using a human SLN probe. One or two main bands were detected in all species tested, except yeast (Fig. 6).

\section{Relationship between SLN and PLN Genes}

The human SLN and PLN (Fujii et al., 1991) genes share common features, consistent with their origin in a common ancestor. Both genes contain two exons and one intron. In both cases, the intron is located about 90 bp downstream of the transcription initiation site, and in both cases it interrupts the ${ }^{\prime}$ untranslated sequence, so that the entire coding sequence is located in exon 2 . The introns are relatively large, about $3.9 \mathrm{~kb}$ long in SLN and about $6 \mathrm{~kb}$ long in PLN. The $3^{\prime}$ ends of both genes contain multiple polyadenylation signals, and more than one polyadenylation site is used in both genes (Fujii et al., 1988). Alignment of human SLN and PLN CDNA reveals $60 \%$ nucleotide identity in the region encoding the predicted transmembrane helices, even though only $30 \%$ identity is observed for the Nterminal and C-terminal domains (not shown).

On the basis of the conservation of amino acids in parts of the N-termini and much of the transmembrane helices of SLN and PLN, we propose that SLN and PLN are homologous proteins. It is possible that they have achieved this degree of sequence identity by convergent evolution, but, in light of the similarity in gene structure, it seems much more likely that sequence similarity is based on divergent evolution from a common gene.

The differences in the $\mathrm{N}$ - and $\mathrm{C}$-terminal sequences of SLN and PLN must reflect their different interactions with different cytoplasmic proteins (PLN is phosphorylated by protein kinase $A$, but SLN is not), but their conserved transmembrane sequences suggest retention of the ability to interact with conserved transmembrane sequences in other proteins. The three SERCA molecules (Burk et al., 1989) are the most likely candidates for such interactions. PLN is coexpressed with SERCA2a and interacts functionally with it. PLN also retains the capacity to inhibit SERCA1 (Toyofuku et al., 1993), but does not do so because the two proteins are not coexpressed in the same tissue. SLN is most highly expressed in fast-twitch muscle, where SE RCA1 is highly expressed and the two proteins copurify (Mac- 
Lennan et al., 1972). In our most recent in vitro coexpression experiments, we have found that SLN inhibits SERCA1 by decreasing its apparent affinity for $\mathrm{Ca}^{2+}$ (A. Odermatt, S. Becker, V. K. Khanna, K. Kurzydlowski, and D. H. MacLennan, unpublished). Since PLN inhibits the activity of SERCA2a by decreasing its apparent affinity for $\mathrm{Ca}^{2+}, \mathrm{SLN}$ may act as the counterpart of PLN in fast-twitch skeletal muscle.

Transmembrane helices M4, M5, and M6, which are key to $\mathrm{Ca}^{2+}$ binding and translocation in SERCA1 (Rice and MacLennan, 1996), are highly conserved in all three SERCA molecules. Thus the three transmembrane sequences in SERCA molecules and the single transmembrane sequence in SLN/PLN molecules may have coevolved, conferring a degree of evol utionary stability on each other. The cytoplasmic domain of PLN also interacts with a cytoplasmic domain of SERCA2a (Toyofuku et al., 1994). This site is conserved in SERCA1, but is missing from SERCA3.

The SLN gene is expressed most abundantly in fasttwitch skeletal muscle (Fig. 5C), the tissue in which SERCA1 is expressed almost exclusively. This is also the tissue from which SLN was first isolated, in association with highly purified SERCA1 (MacLennan et al., 1972). LikeSERCA1 expression (Wu and Lytton, 1993), SLN expression is 10 times lower in slow-twitch skeletal muscle (soleus) than in fast-twitch skeletal muscle (WST, EDL). In cardiac tissue, the concentration of the SLN transcript is about 50-fold less abundant than it is in skeletal muscle (Fig. 5A). SLN expression is another order of magnitude lower in pancreas and prostate (Fig. $5 B$ ), where SERCA2b predominates. PLN is expressed most abundantly in cardiac and slow-twitch skeletal muscle, where SERCA2a is the predominant SERCA molecule, and at much lower levels in fast-twitch skeletal muscle and smooth muscle (Fujii et al., 1988). Thus SLN and PLN are expressed in muscle-specific and complementary patterns, and the patterns of their expression are directly correlated with the expression of different SERCA molecules in each muscle tissue. On the basis of data presented in this paper, we propose that SLN and PLN be recognized as two members of a gene family.

\section{A Potential Role for SLN in Brody Disease}

Kimura et al. (1996) demonstrated that the predicted PLN transmembrane $\alpha$-helix is the inhibitory domain of the PLN molecule. More recently, Kimura et al. (1997) described mutations in the predicted PLN transmembrane $\alpha$-helix that resulted in a dramatic gain of PLN inhibitory function, manifested as a lowering of the apparent affinity of SERCA2a for $\mathrm{Ca}^{2+}$. They proposed that mutations in PLN or SERCA2a that decreased the apparent affinity of SERCA2a for $\mathrm{Ca}^{2+}$ under physiological conditions could lead to cardiomyopathy.

Because a mutant SLN, like a mutant PLN, might gain inhibitory function leading to the morbidity associated with a highly inhibited form of SERCA1, we initiated a search for SLN mutants in the four Brody families with non-ATP2A1-linked Brody disease and with a fifth family available to us. Unfortunately, we did not find any alterations that would support SLN as a candidate gene for Brody disease in these five families.

In additional studies of BD, we showed that two brothers in family BD3, in which ATP2A1 mutations had not been found in an earlier study (Zhang et al., 1995), shared a common haplotype on chromosome 16p12.1- p12.2, suggesting the need for reevaluation of the role of the ATP2A1 gene in the disease. This led us to resequence ATP $2 A 1$ in this family and to the discovery of a fourth BD mutation that would truncate SERCA1. Currently four mutations in three BD families are known, all resulting in recessive inheritance of $B D$. The only recessive $B D$ family that has not been shown to have an ATP2A1 mutation is BD4 (Table 2). We are currently hapl otyping two brothers in this family to determine whether resequencing of ATP2A1 might be warranted. In three other BD families where inheritance is dominant (Table 2), the causal gene has yet to be discovered.

SLN localizes to human chromosome 11q22- q23, a region frequently deleted in several hematological malignancies. In acute leukemias, the MLL (ALL1, HRX, and $H T R X)$ gene, which maps to $11 q 23$, is involved in reciprocal translocations with a large number of gene partners (Bernard and Berger, 1995). Leukemias manifesting 11q23 rearrangements have been shown to be associated with very poor prognosis (Rasio et al., 1996). This region also seems to be sensitive to DN A topoisomerase II inhibitors, as the majority of therapy-related leukemias resulting from treatment with these inhibitors demonstrate MLL rearrangements (Canaani et al., 1995). Cultured cells harboring such deletions might provide an interesting experimental system for the investigation of the function of SLN in cell physiology.

\section{ACKNO WLEDGMENTS}

We are grateful to Drs. Peter Ray and Perry Howard for the generous gift of a human skeletal muscle cDNA library. We also thank Dr. J eremy Squires for helpful advice on chromosomal localization and Stella De Leon for excellent technical support. Early studies on this topic, initiated by Mr. David Price, are gratefully acknowledged.

This work was supported by grants to D.H.M. from the Muscular Dystrophy Association of Canada, the Canadian Genetic Diseases Network of Centers of Excellence and the Medical Research Council of Canada (MRCC). A.O. was a Postdoctoral fellow of the MRCC.

\section{REFERENCES}

Ausubel, F. M., Brent, R., Kingston, R. E., Moore, D. D., Seidman, F. G., Smith, A., and Struhl, K. (1994). In, "Current Protocols in Molecular Biology," Wiley-Interscience, NY.

Benders, A.A.G.M., Veerkamp, J.H., Oosterhof, A., J ongen, P.J.H., Bindels, R. J.M., Smit, L. M. E., Busch, H.F.M., and Wevers, R. A. (1994). Ca ${ }^{2+}$ homeostasis in Brody's disease. A study 
in skeletal and cultured muscle cells and the effects of dantrolene and verapamil. J. Clin. Invest. 94: 741- 748.

Bernard, O. A., and Berger, R. (1995). Molecular basis of 11q23 rearrangements in hematopoietic malignant proliferations. Genes Chromosomes and Cancer 13: 75-85.

Brody, I. A. (1969). Muscle contracture induced by exercise. A syndrome attributable to decreased relaxing factor. N. Engl. J . Med. 281: 187- 192.

Burk, S. E., Lytton, J ., MacLennan, D. H., and Shull, G. E. (1989). cDNA cloning, functional expression, and mRNA tissue distribution of a third organellar $\mathrm{Ca}^{2+}$ pump. J . Biol. Chem. 264: 1856118568.

Canaani, E., Nowell, P. C., and Croce, C. M. (1995). Molecular genetics of 11q23 chromosometranslocations. Adv. Cancer Res. 66: 213234.

Chomczynski, P., and Sacchi, N. (1987). Single-step method of RNA isolation by acid guanidinium thiocyanate- phenol - chloroform extraction. Anal. Biochem. 162: 156-159.

Danon, M. J ., Karpati, G., Charuk, J ., and Holland, P. (1988). Sarcoplasmic reticulum adenosinetriphosphatase deficiency with probable autosomal dominant inheritance. Neurology 38: 812-815.

Dubois, B. L., and Naylor S. (1993). Characterization of NIGMS human/rodent somatic cell hybrid mapping panel 2 by PCR. Genomics 16:315- 319.

Fujii, J ., Lytton, J ., Tada, M., and MacLennan, D. H. (1988). Rabbit cardiac and slow-twitch muscle express the same phospholamban gene. FEBS Lett. 227: 51-55.

Fujii, J ., Zarain-Herzberg, A., Willard, H. F., Tada, M., and MacLennan, D. H. (1991). Structure of the rabbit phospholamban gene, cloning of the human CDNA, and assignment of the gene to human chromosome 6. J . Biol. Chem. 266: 11669-11675.

Giovanna, P., J ardine, K., and McBurney, M. W. (1991). Multiple CArG boxes in the human cardiac actin gene promoter required for expression in embrionic cardiac muscle cells developing in vitro from embryonal carcinoma cells. Mol. Cell. Biol. 11: 4796-4803.

Heng, H.H., and Tsui, L.C. (1993). Modes of DAPI banding and simultaneous in situ hybridization. Chromosoma 102: 325-332.

Hidaka, K., Yamamoto, I., Arai, Y., and Mukai, T. (1993). The MEF3 motif is required for MEF-2 mediated skeletal muscle-specific induction of the rat aldolase A gene. Mol. Cell. Biol. 13: 64696478.

Hudson, T.J ., Stein, L. D., Gerety, S. S., Ma, J ., Castle, A. B., Silva, J ., Slonim, D., Baptista, R., Kuglyak, L., Xu, S-H., Hu, X., Colbert, A. M. E., Rosenberg, C., Reeve-Daly, M., Rozen, S., Hui, L., Wu, X., Vestergaard, C., Wilson, K. M., Bae, J . S., Maitra, S., Ganiastsas, S., Evans, C. A., DeAngelis, M. M., Ingalls, K. A., Nahf, R. W., Horton, R. T., Oskin Anderson, M., Collymore, A. J ., Ye, W., Kouyoumjian, V. Zemstava, I. S., Tam, J ., Devine, R., Courtney, D. F. Turner Renaud, M., Nguyen, H., O'Connor, T.J., Fizames, C., Faure, S., Gyapy, G., Dib, C., Morrissette, J ., Orlin, J . B., Birren, B. W., Goodman, N., Weissenbach, J ., Hawkins, T. L., Foote, S., Page, D. C., and Lander, E.S. (1995). An STS-based map of the human genome. Science 270:1945- 1954.

Innis, M. A., Gelfa, D. H., Sninsky, J .J ., and White, T.J . (1990). "PCR Protocols: A Guide to Methods and Applications," Academic Press, San Diego.

Karpati, G., Charuk, J ., Carpenter, S., J ablecki, C., and Holland, P. (1986). Myopathy caused by a deficiency of $\mathrm{Ca}^{2+}$-adenosinetriphosphatase in sarcoplasmic reticulum (Brody's disease). Ann. Neurol. 20: 38-49.

Kimura, Y., Kurzydlowski, K., Tada, M., and MacLennan, D. H. (1996). Phosholamban regulates the $\mathrm{Ca}^{2+}$ ATPase through intramembrane interactions. J. Biol. Chem. 271: 21726- 21731.

Kimura Y., Kurzydlowski, K., Tada, M., and MacLennan, D. H. (1997). Phosholamban inhibitory function is activated by depolymerization. J . Biol. Chem. 272: 15061- 15064.
Korczak, B., Zarain-Herzberg, A., Brandl, C. J ., Ingles, C. J ., Green, N. M., and MacLennan, D. H. (1988). Structure of the rabbit fasttwitch skeletal muscle $\mathrm{Ca}^{2+}$-ATPase gene. J . Biol. Chem. 263: 4813-4819.

Kozak, M. (1987). An analysis of 5'-noncoding sequences from 699 vertebrate messenger RNAs. Nucleic Acids Res. 15: 8125-8148.

Lamballe, F., Klein, R., and Barbacid, M. (1991). trkC, a new member of the trk family of tyrosine protein kinases, is a receptor for neurotrophin-3. Cell 66: 967-979.

Lee, W., Mitchell, P., and Tjian, R. (1987). Purified transcription factor AP-1 interacts with TPA-inducible enhancer elements. Cell 49: $741-752$.

Lewin, B. (1994). “Genes V," Oxford Univ. Press, New York.

Lichter, P., Ledbetter, S. A., Ledbetter, D. H., and Ward, D. C. (1990). Fluorescence in situ hybridization with Alu and L1 polymerase chain reaction probes for rapid characterization of human chromosomes in hybrid cell lines. Proc. Natl. Acad. Sci. USA 87: 66346638.

MacLennan, D. H., Yip, C. C., Iles, G. H., and Seeman, P. (1972). I solation of sarcoplasmic reticulum proteins. Cold Spring Harbor Symp. Quant. Biol. 37, 469-478.

MacLennan, D. H., Reithmeier, R. A., Shoshan, V., Campbell, K. P., LeBel, D., Herrmann, T. R., and Shamoo, A. E. (1980). I on pathways in proteins of the sarcoplasmic reticulum. Ann. N. Y. Acad. Sci. 358: 138- 140.

MacLennan, D. H., Brandl, C. J., Korczak, B., and Green, N. M. (1985). Amino-acid sequence of a $\mathrm{Ca}^{2+}-\mathrm{Mg}^{2+}$-dependent ATPase from rabbit sarcoplasmic reticulum, deduced from its complementary DNA sequence. Nature 316: 696-700.

Maruyama, K., and MacLennan, D. H. (1988). Mutation of aspartic acid-351, Iysine-352, and lysine 515 alters the $\mathrm{Ca}^{2+}$ transport activity of the $\mathrm{Ca}^{2+}$ - ATPase expressed in COS-1 cells. Proc. Natl. Acad. Sci. USA. 85: 3314- 3318.

Navarre, C., Ghislain, M., Leterme, S., Ferroud, C., Dufour, J .-P., and Goffeau, A. (1992). Purification and complete sequence of a small proteolipid associated with the plasma membrane $\mathrm{H}^{+}$ATPase of Saccharomyces cerevisiae. J . Biol. Chem. 267: 64256428.

Navarre, C., Catty, P., Leterme, S., Dietrich, F., and Goffeau, A. (1994). Two distinct genes encode small isoproteolipids affecting plasma membrane $\mathrm{H}^{+}$-ATPase activity of Saccharomyces cerevisiae. J . Biol. Chem. 269: 21262-21268.

Odermatt, A., Taschner, P. E. M., Khanna, V. K., Busch, H. F. M., Karpati, G., J ablecki, C. K., Breuning, M.H., and MacLennan, D. H. (1996). Mutations in the gene encoding SERCA1, the fasttwitch skeletal muscle sarcoplasmic reticulum $\mathrm{Ca}^{2+}$ ATPase, are associated with Brody disease. Nature Genet 14: 191- 194.

Okayama, H., and Berg, P. (1983). A cDNA cloning vector that permits expression of CDNA inserts in mammalian cells. Mol. Cell. Biol. 3: 280- 289.

Phillips, M. S., Fujii, J ., Khanna, V. K., Deleon, S., Yokobata, K., De J ong, P. J ., and MacLennan, D. H. (1996). The structural organization of the human skeletal muscle ryanodine receptor (RYR1) gene. Genomics 34: 24- 41.

Piette, J ., Bessereau, J -J ., Huchet, M., and Changeux, J -P. (1990). Two adjacent $\mathrm{MyoD1}$-binding sites regulate expression of the acetylcholine receptor $\alpha$-subunit gene. Nature 345: 353- 355.

Poels, P.J.E., Wevers, R. A., Braakhekke, J.P., Benders, A. A. G. M., Veerkamp, J . H., and J oosten, E. M. G. (1993). Exertional rhabdomyolysis in a patient with calcium adenosine triphosphatase deficiency. J . Neurol. Neurosurg. Psychiatry 56: 823-826.

Racker, E., and Eytan, E. (1975). A coupling factor from sarcoplasmic reticulum required for the translocation of $\mathrm{Ca}^{2+}$ ions in a reconstituted $\mathrm{Ca}^{2+}$ ATPase pump. J . Biol. Chem. 250: 7533- 7534.

Rasio, D., Schichman, S. A., Negrini, M., Canaani, E., and Croce, 
C. M. (1996). Complete exon structure of the ALL1 gene. Cancer Res. 54: 1766- 1769.

Rice, W. R., and MacLennan, D. H. (1996). Scanning mutagenesis reveals a similar pattern of mutation sensitivity in transmembrane sequences M4, M5 and M6, but not in M8 of the $\mathrm{Ca}^{2+}$-ATPase of sarcoplasmic reticulum (SERCA1a). J . Biol. Chem. 271, 3141231419.

Shaw, G., and Kamen, R. (1986). A conserved AU sequence from the $3^{\prime}$ untranslated region of GM-CSF mRNA mediates selective mRNA degradation. Cell 46: 659-667.

Tada, M., and Katz, A. M. (1982) Phosphorylation of the sarcoplasmic reticulum and sarcolemna. Annu. Rev. Physiol. 44: 401-423.

Taylor, D. J ., Brosnan, M. J ., Arnold, D. L., Bore, P.J ., Styles, P., Walton, J ., and Radda, G. K. (1988). $\mathrm{Ca}^{2+}$-ATPase deficiency in a patient with an exertional muscle pain syndrome. J . Neurol. Neurosurg. Psychiatry 51: 1425- 1433 (1988).

Toyofuku, T., Kurzydlowski, K., Tada, M., and MacLennan, D. H. (1993). I dentification of regions in the $\mathrm{Ca}^{2+}$ ATPase of sarcoplasmic reticulum that affect functional association with phospholamban. J . Biol. Chem. 268: 2809-2815.

Toyofuku, T., Kurzydlowski, K., Tada, M., and MacLennan, D. H. (1994). Amino acids Lys-Asp-Asp-Lys-Pro-Val ${ }^{402}$ in the $\mathrm{Ca}^{2+}$ ATPase of cardiac sarcoplasmic reticulum are critical for functional association with phospholamban. J . Biol. Chem. 269: 22929- 22932.
Walter, M., Spillet, D., Thomas, P., Weissenbach, J ., and Goodfellow, P. (1994). A method for constructing radiation hybrid maps of whole genomes. Nature Genet. 7:22- 28.

Wawrzynow, A., Theibert, J . L., Murphy, C., J ona, I., Martonosi, A., and Collins, J . H. (1992). Sarcolipin, the "proteolipid" of skeletal muscle sarcoplasmic reticulum, is a unique, amphipathic, 31-residue peptide. Arch. Biochem. Biophys. 298: 620-623.

Weintraub, H., Davis, R., Lockshon, D., and Lassar, A. (1990). MyoD binds cooperatively to two sites in a target enhancer sequence: Occupancy of two sites is required for activation. Proc. Natl. Acad. Sci. USA 87: 5623-5627.

Wevers, R.A., Poels, P.J.E., J oosten, E. M. G., Steenbergen, G. G. H., Benders, A. A. G. M., and Veerkamp, J.H. I (1992). Ischaemic forearm testing in a patient with $\mathrm{Ca}^{2+}$-ATPase deficiency. J . Inher. Metab. Dis. 15: 423-425.

Wu, K-D., and Lytton, J . (1993). Molecular cloning and quantification of sarcoplasmic reticulum $\mathrm{Ca}^{2+}$-ATPase isoforms in rat muscles. Am. J . Physiol. 264: C333-C341. [Cell Physiol. 33]

Zhang, Y., Fujii, J ., Phillips, M. S., Chen, H. S., Karpati, G., Yee, W. C., Schrank, B., Cornblath, D. R., Boylan, K. B., and MacLennan, D. H. (1995). Characterization of CDNA and genomic DNA encoding SERCA1, the $\mathrm{Ca}^{2+}$-ATPase of human fast-twitch skeletal muscle sarcoplasmic reticulum, and its elimination as a candidate gene for Brody disease in three patients. Genomics 30: 415- 424. 